\title{
Safety, Efficacy, and Physicochemical Characterization of Tinospora crispa Ointment: A Community-Based Formulation against Pediculus humanus capitis
}

\author{
Gerwin Louis Tapan Dela Torre', Kerstin Mariae Gonzales Ponsaran', Angelica Louise Dela Peña de Guzman', \\ Richelle Ann Mallapre Manalo', Erna Custodio Arollado, ${ }^{1,2, *}$ \\ 1/nstitute of Pharmaceutical Sciences, National Institutes of Health, University of the Philippines Manila, Ermita, Manila 1000, the Philippines; \\ ${ }^{2}$ Department of Pharmacy, College of Pharmacy, University of the Philippines Manila, Ermita, Manila 1000, the Philippines
}

\begin{abstract}
The high prevalence of pediculosis capitis, commonly known as head lice (Pediculus humanus capitis) infestation, has led to the preparation of a community-based pediculicidal ointment, which is made of common household items and the extract of Tinospora crispa stem. The present study aimed to evaluate the safety, efficacy, and physicochemical characteristics of the T. crispa pediculicidal ointment. The physicochemical properties of the ointment were characterized, and safety was determined using acute dermal irritation test (OECD 404), while the efficacy was assessed using an in vitro pediculicidal assay. Furthermore, the chemical compounds present in T. crispa were identified using liquid-liquid extraction followed by ultra-performance liquid chromatography quadruple time-of-flight mass spectrometric (UPLC-qTOF/ MS) analysis. The community-based ointment formulation was light yellow in color, homogeneous, smooth, with distinct aromatic odor and $\mathrm{pH}$ of $6.92 \pm 0.09$. It has spreadability value of $15.04 \pm 0.98 \mathrm{~g} \cdot \mathrm{cm} / \mathrm{sec}$ and has thixotropic behavior. It was also found to be non-irritant, with a primary irritation index value of 0.15 . Moreover, it was comparable to the pediculicidal activity of the positive control Kwell ${ }^{\circledR}$, a commercially available $1 \%$ permethrin shampoo $(P>0.05)$, and was significantly different to the activity of the negative control ointment, a mixture of palm oil and candle wax $(P<0.05)$. These findings suggested that the community-based T. crispa pediculicidal ointment is safe and effective, having acceptable physicochemical characteristics. Its activity can be attributed to the presence of compounds moupinamide and physalin I.
\end{abstract}

Key words: Pediculus humanus capitis, Tinospora crispa, dermal irritation, ointment, pediculicidal assay

\section{INTRODUCTION}

Pediculosis capitis (head lice infestation) is the most common type of pediculosis [1], an ectoparasitic disease in humans [2]. It is caused by the infestation of head lice (Pediculus humanus capitis) [3], a 6-legged, blood sucking, wingless insect that thrives on human scalp [4] (Fig. 1). Head lice are common among children aged 3-11 years, which can be transmitted through either direct (head-to-head) contact with the infested person or indirectly through personal items, such as combs, hats, scarfs, beddings and towels [5]. Pediculosis capitis presents a public health problem [6] as it can cause social stigma, embarrassment, low self-esteem, loss of productivity,

\footnotetext{
- Received 11 May 2017, revised 16 July 2017, accepted 19 July 2017.

*Corresponding author (ecarollado@up.edu.ph)

(C) 2017, Korean Society for Parasitology and Tropical Medicine

This is an Open Access article distributed under the terms of the Creative Commons

Attribution Non-Commercial License (http://creativecommons.org/licenses/by-nc/4.0) which permits unrestricted non-commercial use, distribution, and reproduction in any

medium, provided the original work is properly cited.
}

and frustration among afflicted individuals [7]. It is not generally associated with morbidity [7] and is not currently considered to be vectors for human pathogens [8], but secondary bacterial infections may occur as a result of subsequent skin excoriation due to sensitization to louse saliva [6].

A number of both over-the-counter and prescription formulations are available for the treatment of pediculosis capitis. These includes permethrin, pyrethrin, malathion, and lindane. However, their use to control pediculosis globally has been hampered due to the growing issues concerning the aforementioned treatments [7]. There have been records of resistance in many parts of the world due to a large treatment selection pressure induced by conventional pediculicides. Resistance contributes to treatment failures, which may result in chronic infestations [9]. In addition, these chemicals are neurotoxic [10] and cause pruritus, erythema, and edema [11]. With the associated treatment failures, drug resistance, and side effects of the currently available pediculicides, the search for safe and effective alternative pediculicidal agents are comprehensively conducted. 


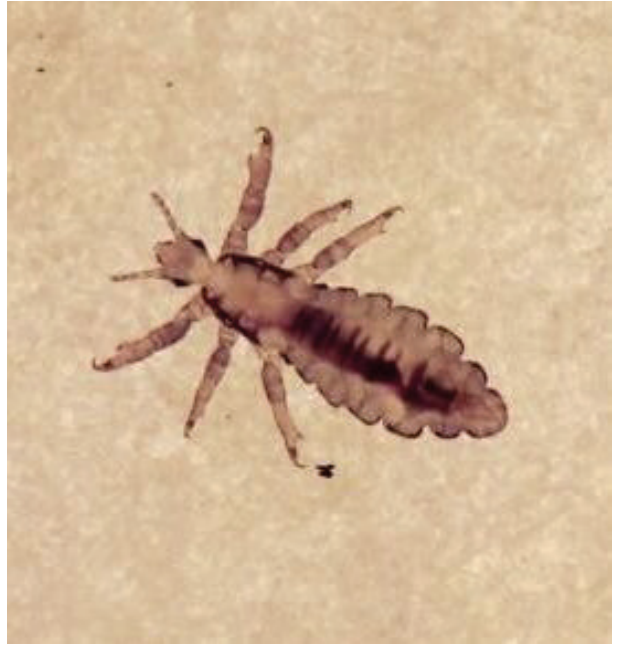

Fig. 1. Microscopic picture of an adult Pediculus humanus capitis (head louse).

In the Philippines, the burden of pediculosis capitis among schoolchildren was considered high at 54.7\% during 1986 [12]. The disease burden increased significantly to $84 \%$ in the year 2000, and in 2012, it was named as the second highest medical problem among schoolchildren after tooth decay [13]. At the present time, the growing problem on pediculosis capitis still persists. In this aspect, communities have resorted to formulate their own pediculicidal treatment to resolve the high prevalence of the disease. Community-based pediculicidal ointment formulation was documented by the Philippine Institute of Traditional and Alternative Health Care (PITAHC) utilizing common household items and the extract of Tinospora crispa stem as the active constituent [14]. The selection of $T$. crispa may be attributed to its wide distribution throughout the Philippines [15] and its traditional use as an anti-parasitic agent on humans and domestic animals [16].

The aim of this work was to evaluate the safety and efficacy of the community-based ointment preparation containing $T$. crispa extract against head lice, and characterize its physicochemical properties.

\section{MATERIALS AND METHODS}

\section{Plant sample}

Fresh T. crispa stems were collected from the town of Alabat, in the province of Quezon, Philippines. The plant was identified to be T. crispa by the National Museum of the Philippines - Botany Division and was given a voucher specimen no. 1604-352.

\section{Preparation of $T$. crispa ointment}

The fresh stems of T. crispa were garbled and washed with water to remove any clinging dirt and insect debris. The preparation of the ointment followed a community-based formula [14]. The stems were chopped into small pieces. In a pot, a cup of the chopped stems, together with a cup of palm oil, were boiled for $15 \mathrm{~min}$ for the extraction of active constituents from the stem. The oil extract was then filtered, and 1 white, unscented, pulverized candle (diameter-1 cm; length-14.5 $\mathrm{cm}$ ) was incorporated to the oil extract through continuous stirring under the temperature range of $50-60^{\circ} \mathrm{C}$. It was then transferred on opaque ointment jars, after the candle has completely melted.

\section{Characterization of $T$. crispa ointment}

The T. crispa ointment was subjected to physicochemical tests of homogeneity, color, odor and $\mathrm{pH}$. Spreadability measurement was performed using the "slip" and "drag" characteristics of the ointment [17]. Rheological behavior was determined using Brookfield Viscometer (Spindle - LV3) at $25^{\circ} \mathrm{C}$.

\section{Experimental animals}

Adult healthy albino rabbits of both sexes (8-10 weeks old; $1.5-2.0 \mathrm{~kg}$ ) were procured from the St. Luke's Medical Center, Research \& Biotechnology Division (Quezon City, Philippines). The rabbits were housed individually at the animal facility of the National Institutes of Health, maintained in a controlled room temperature $\left(23-25^{\circ} \mathrm{C}\right)$ under $12 \mathrm{hr} / 12 \mathrm{hr}$ light/ dark cycle, with commercial rabbit pellet and water supplied ad libitum. Acclimatization was done 1 week before the dermal irritation test. The experimental procedure was approved by the Institutional Animal Care and Use Committee (IACUC) of the University of the Philippines Manila (IACUC protocol no. 2016-022).

\section{Dermal irritation test}

Acute dermal irritation study was carried out using the OECD guideline 404 [18] with some modifications. Four rabbits ( 2 male and 2 female) were used in the study. Six areas of approximately $6 \mathrm{~cm}^{2}, 3$ on each side of the dorsal area of each rabbit, were shaved $24 \mathrm{hr}$ before the test. The shaved areas on the left side were applied with $0.5 \mathrm{~g}$ of $T$. crispa ointment using a sterile cotton swab and held in place with a gauze patch and non-irritating tape. The shaved areas on the right side served as the control and received $0.5 \mathrm{~g}$ of the negative control ointment 
Table 1. Grading of skin reactions

\begin{tabular}{|c|c|c|c|}
\hline Erythema and eschar formation & & Edema formation & \\
\hline No erythema & 0 & No edema & 0 \\
\hline Very slight erythema (barely perceptible) & 1 & Very slight edema & 1 \\
\hline Well defined erythema & 2 & Slight edema (edges of area well defined by definite rating) & 2 \\
\hline Moderate to severe erythema & 3 & Moderate edema (raised approximately $1 \mathrm{~mm}$ ) & 3 \\
\hline $\begin{array}{l}\text { Severe erythema (beef redness) to eschar formation } \\
\text { preventing grading of erythema }\end{array}$ & 4 & $\begin{array}{l}\text { Severe edema (raised more than } 1 \mathrm{~mm} \text { and extending beyond } \\
\text { area of exposure) }\end{array}$ & 4 \\
\hline
\end{tabular}

(palm oil and pulverized candle only). After $4 \mathrm{hr}$, the gauze patches were removed and the shaved areas were rinsed with distilled water. The test areas were examined at approximately $1,24,48$, and $72 \mathrm{hr}$ after the removal of gauze for evidences of primary irritation and scored according to the scale used in the OECD guideline 404 (Table 1).

Primary irritation index (PII) was calculated by dividing the sum of erythema and edema scores, with the product of the number of test sites and the number of grading intervals [19]. It was then classified according to Draize method of classification using PII scoring as non-irritant (if PII $<0.5$ ), slightly irritant (if PII $<2$ ), moderately irritant (if PII $<2-5$ ), and severely irritant (if PII > 5) [20].

\section{Ethical Consideration}

The study was reviewed and approved by the University of the Philippines Manila Review and Ethics Board (UPMREB) and was given the study code no. UPMREB 2016-277-01. Prior to screening and collection of head lice, verbal assent was obtained from the children and informed written consent was secured from their parents or guardians. All children and their families were given an over-the-counter 1\% permethrin shampoo (Kwell ${ }^{\circledR}$ ) after the study.

\section{Screening of schoolchildren with head lice}

Schoolchildren aged 5-11, of either sex around the 5th District of Manila, were screened for their possible inclusion in the study. Screening was made by the parent or guardian of the child. The hair was divided into 4 quadrants by a plastic head lice comb. Next, the hair on each quadrant was combed 6 times starting from the scalp and ending at the hair tips [21]. The number of lice collected was counted. Children with at least 5 living lice and did not use any form of pediculicidal agents in the previous month were included in the study.

\section{Head lice collection}

Adult head lice were collected from the screened schoolchil- dren. The parents or guardians extracted the head lice at the day of the researcher's visit to ensure the viability of the insects. Head lice were placed over a plastic container covered with filter paper, moistened with distilled water to prevent death by desiccation. The collected head lice were transported to the Institute of Pharmaceutical Sciences' laboratory for the in vitro assay. Only fully active and intact adult head lice with the size range of 2-3 $\mathrm{mm}$ long were used, irrespective of sex. Within an hour after the collection, the assay was performed.

\section{In vitro pediculicidal assay}

The T. crispa ointment was tested for its pediculicidal activity along with the negative control ointment (palm oil and pulverized candle only) and positive control (1\% permethrin shampoo, Kwell ${ }^{\circledR}$ ). A total of 252 head lice were used in the study ( $\mathrm{n}=84$ per group). The analyses were tested in batches of $84\left(n=28\right.$ per group) at room temperature $\left(25 \pm 3^{\circ} \mathrm{C}\right)$. Petri dishes lined with filter paper were prepared. Head lice were then placed on the filter paper together with some hair strands. To prevent the desiccation of head lice, the filter papers were moistened with distilled water. Samples were introduced through direct application. Each louse received either $15 \mathrm{mg}$ of T. crispa ointment, $15 \mathrm{mg}$ of negative control or a single drop of the positive control. After $20 \mathrm{~min}$ of exposure to the samples, the head lice were washed with tap water to simulate treatment on an infested host. Afterwards, head lice were placed into new petri dishes with unused moistened filter papers and were examined under a dissecting microscope. Three pre-defined criteria for the evaluation of the pediculicidal activity of samples were used. Lice were defined as 'active' if no changes in the activity or behavior were observed post-treatment. In the 'some vital signs' category, the reduced activity was shown by the inability of the lice to walk in a progressive fashion and the absence of righting reflex when rolled onto the back, but still with peristalsis. Lastly, the complete absence of any vital signs such as peristalsis and movement of antennae or legs, even after stimulating with a single hair strand, 
were defined as 'no vital signs'. Observations were conducted at $30,60,90,120,150$, and 180 min post-treatment [22,23].

\section{Compound identification}

The solution ( $50 \mathrm{ml}$ ) obtained from the T. crispa extraction with palm oil was extracted 3 times with equal amount of dimethylsulfoxide (DMSO). The DMSO portion was pooled and was diluted to $5 \%$ using distilled water. The solution was filtered using $0.2 \mu \mathrm{m}$ syringe filter. Palm oil underwent the same treatment and was used as blank. The resulting filtrates were subjected to ultra-performance liquid chromatography quadruple time-of-flight mass spectrometric (UPLC-qTOF/ MS) analysis for the identification of compounds present [24].

UPLC-qTOF/MS analysis was performed using Waters Acquity $^{\mathrm{TM}} \mathrm{UPLC}^{\mathrm{TM}}$ I-Class/Xevo equipped with Xevo G2-XS qTOF mass spectrometer. Chromatographic separation was performed using Waters HSS T3 C18 column $(2.1 \times 100 \mathrm{~mm}$ i.d., $1.8 \mu \mathrm{m})$ maintained at $40^{\circ} \mathrm{C}$. The mobile phase was composed of acetonitrile $+0.1 \%$ formic acid (A) and water $+0.1 \%$ formic acid (B). The following gradient program was employed: 5\% A for $0.5 \mathrm{~min}$, linearly increased to $95 \%$ A for $10 \mathrm{~min}$, followed by an isocratic phase for $4.5 \mathrm{~min}$, then $99 \% \mathrm{~A}$ for $2.5 \mathrm{~min}$ and linearly decreased to 5\% A for $25 \mathrm{~min}$. The flow rate $0.4 \mathrm{ml} /$ min and the injection volume was $5 \mu \mathrm{l}$.

The Waters Xevo G2-XS qTOF MS ${ }^{\mathrm{E}}$ was run in positive ion mode. The capillary and cone voltages were set to $1.0 \mathrm{kV}$ and $40 \mathrm{~V}$, respectively, with the cone gas flow at $40 \mathrm{~L} / \mathrm{hr}$. The desolvation temperature was $550^{\circ} \mathrm{C}$, gas flow at $950 \mathrm{~L} / \mathrm{hr}$, and source temperature at $120^{\circ} \mathrm{C}$. Data were collected between the mass range of 100 and 1,200 Da, with a scan time of 0.150 sec. MS analysis was carried out to identify the compounds present in the T. crispa extract and the data were processed using UNIFI Scientific Information System with the Traditional Chinese Medicine Library (TCML) for identification of putative compounds present in the sample.

\section{Statistical analysis}

The data were expressed as mean \pm standard error of the mean (SE). The differences between groups per observation time were compared by 1-way analysis of variance (ANOVA) followed by Tukey's post-hoc test. To investigate the efficacy between T. crispa ointment and positive control over time, 2-way mixed ANOVA was used. All statistical analyses were performed using the Statistical Package for the Social Sciences (SPSS, Chicago, Illinois, USA) 23.0. Results with $P<0.05$ were considered statistically significant.

\section{RESULTS}

\section{Characterization of $T$. crispa ointment}

The community-based formulation of T. crispa ointment was light yellow, smooth and homogenous, having a distinctive aromatic odor and $\mathrm{pH}$ of $6.92 \pm 0.09$. It has a spreadability value of $15.04 \pm 0.98 \mathrm{~g} . \mathrm{cm} / \mathrm{sec}$. Rheological study revealed that the ointment has a thixotropic behavior (Fig. 2).

\section{Pediculicidal activity study}

The results of the in vitro pediculicidal assay are shown in Fig. 3. It was observed that all groups displayed fluctuations in their activities over time except for active head lice group treated with T. crispa ointment. For the active head lice group, the $T$. crispa ointment treatment showed comparable activity with the positive control at $30(P=0.728), 60(P=0.165), 90(P=$ 0.214), $120(P=0.240), 150(P=0.096)$, and $180(P=0.056)$ $\min$ (Fig. 3A). On the other hand, positive control and T. crispa ointment treatment groups demonstrated significantly different activities with negative control at all observation times $(P<0.05)$. Comparable activities were also observed in the head lice group with some vital signs treated with $T$. crispa ointment relative to positive $(P>0.05)$ and negative $(P>0.05)$ controls (Fig. 3B) at all time points. The mortality or the number of head lice with no vital signs treated with T. crispa ointment decreased over time but displayed comparable activity with the positive control at $30(P=0.961), 60(P=0.229), 90$ $(P=0.416), 120(P=0.334), 150(P=0.278)$, and $180(P=$ $0.131) \mathrm{min}$ (Fig. 3C). Significantly different activities in the mortality of head lice were observed in positive and T. crispa ointment treatment groups in comparison to the negative control $(P<0.05)$. It should be noted that at 30 min observation

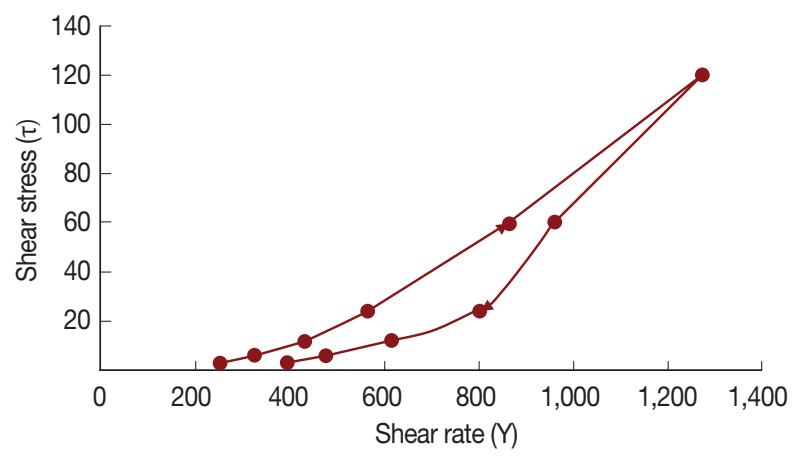

Fig. 2. Rheogram of Tinospora crispa ointment at $25^{\circ} \mathrm{C}$. 
A
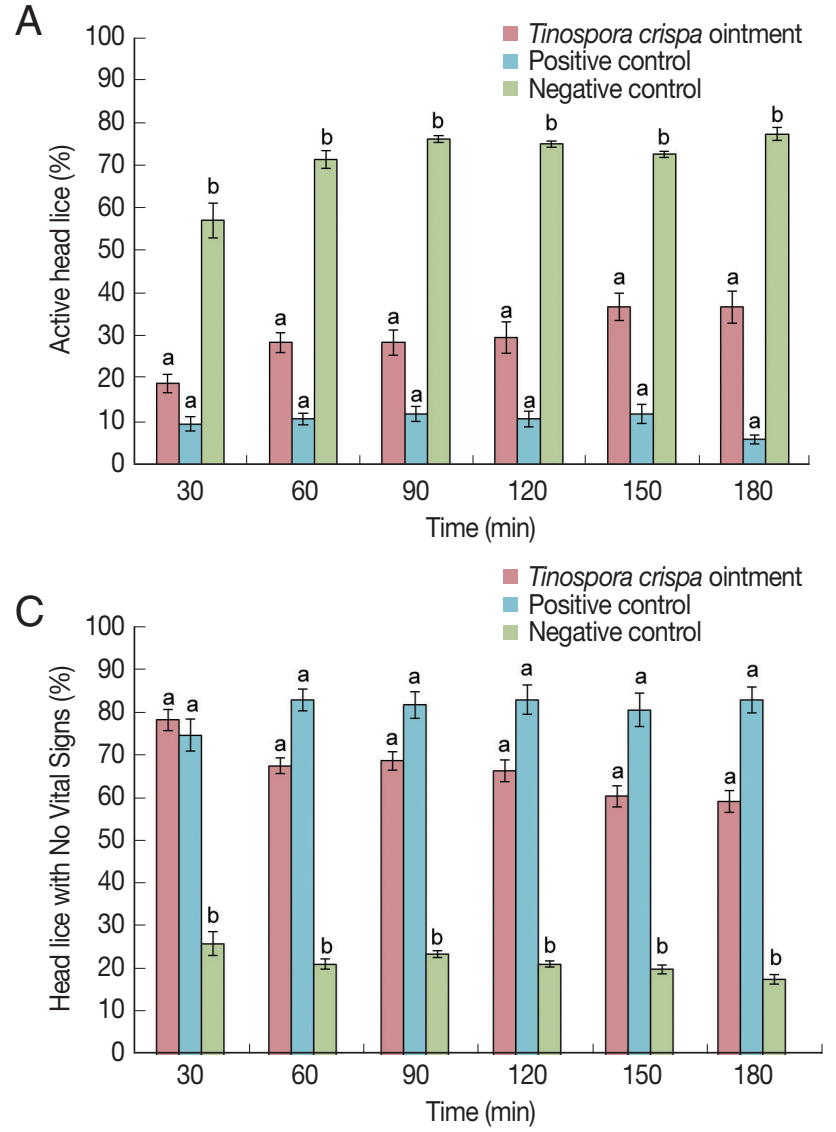

Tinospora crispa extract
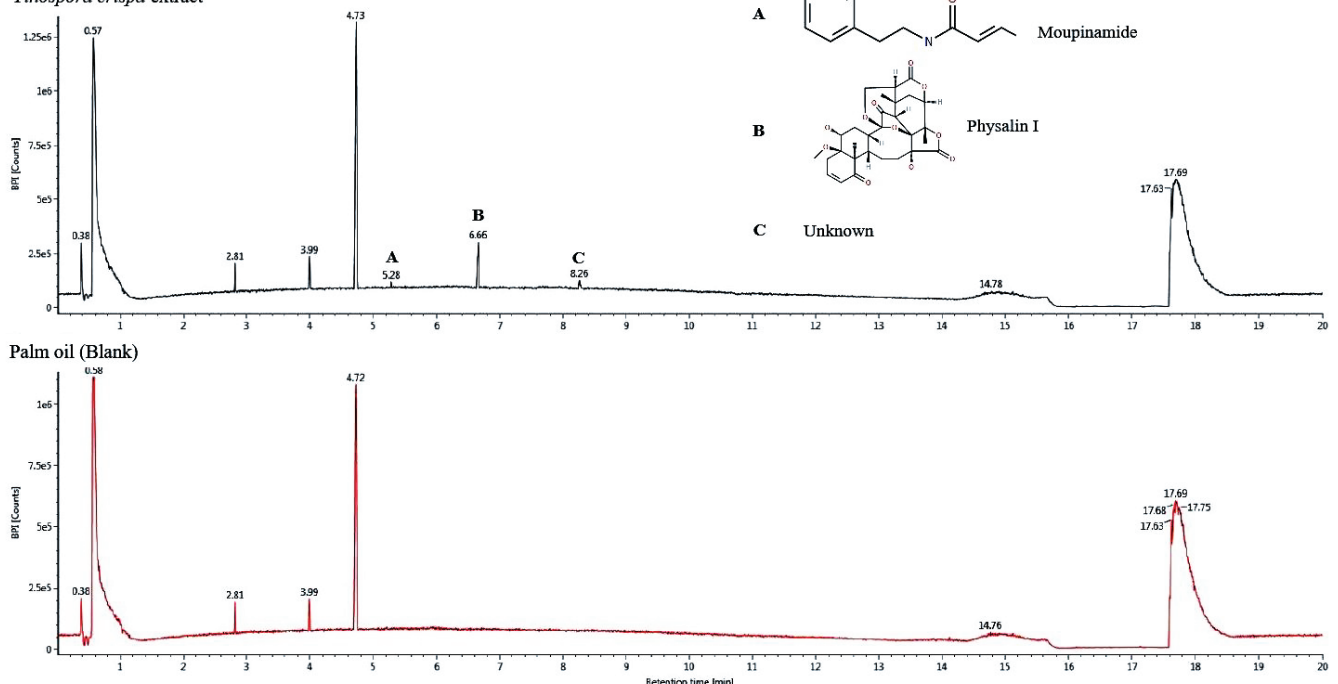

B 30 - Tinospora crispa ointment

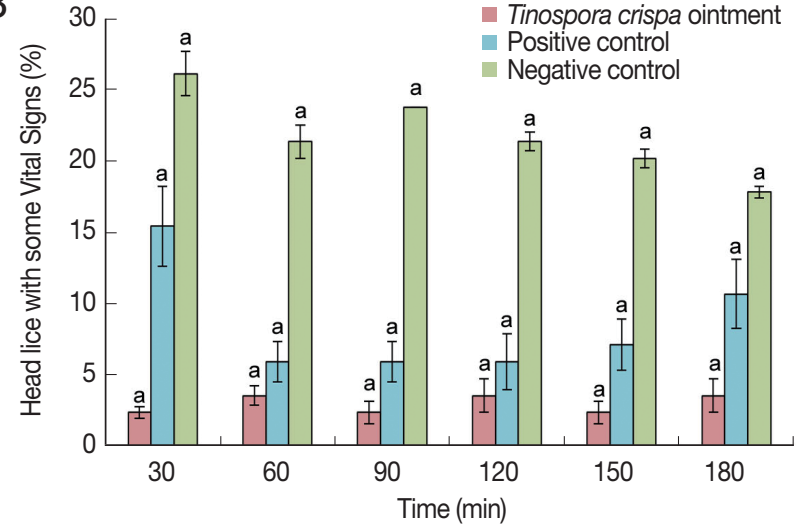

Fig. 3. Percent activity of T. crispa ointment, positive control (1\% permethrin, Kwell ${ }^{\otimes}$ shampoo) and negative control ointment (palm oil+pulverized candle) on head lice. (A) Percentage of head lice that are active, post-treatment. (B) Percentage of head lice considered having 'some vital signs', post-treatment. (C) Percentage mortality of head lice considered having 'no vital signs', posttreatment. Different lower case letters in mean significantly different, $P<0.05$, whereas similar letters mean not significantly different from each other.

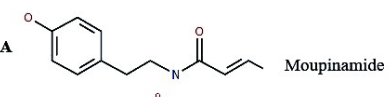

. 
with the positive control $(\overline{\mathrm{x}}=81.35 \%)$ and T. crispa ointment $(\bar{x}=67.06 \%)$ performing slightly similar overall activities.

\section{Dermal irritation test}

All the rabbit's skin areas treated with negative control ointment were devoid of both erythema and edema, thus, having a PII value of 0.00 . No signs of edema but with a very slight erythema on a single area of all rabbits were observed an hour after the application of T. crispa ointment, which disappeared thereafter. It was classified as a non-irritant formulation because of the PII value of 0.15 . Additionally, the skin of the rabbits on all areas tested were intact throughout the $72 \mathrm{hr}$ study duration.

\section{Compound identification}

T. crispa oil extract was analyzed by UPLC-qTOF/MS for compound identification, using palm oil as blank. The chromatogram generated is shown in Fig. 4. It was observed that there were 3 distinct peaks in the T. crispa extract as compared to palm oil, with retention times at 5.28, 6.66 and $8.26 \mathrm{~min}$. Using the TCML, the compound with retention time of 5.28 min and an observed mass of 313.1311 Da was identified to be moupinamide, while the compound with retention time of 6.66 and an observed mass of 558.2083 Da was recognized to be physalin I. Although the last compound with retention time of 8.26 min was not identified from the TCML, it was known to have an observed $\mathrm{m} / \mathrm{z}$ of 230.2471 .

\section{DISCUSSION}

Pediculosis capitis has been well-known since antiquity [25] and hitherto, remains a public health problem worldwide [26]. With the presence of resistance to conventional pediculicidal agents [9], the combat against head lice became more difficult. To address the problem, the search for alternative treatments were initiated, focusing on natural products as they can provide good pediculicidal activity and can offer a valid alternative to conventional treatments [27]. In the Philippines, a community-based ointment formulation against head lice is currently being used. The ointment is composed of edible oil and candle wax as bases, and T. crispa extract as active ingredient [14]. The formulation has an almost neutral $\mathrm{pH}$ value range of $6.92 \pm 0.09$, which is close to $\mathrm{pH}$ value range of the skin ( $\mathrm{pH} 4.0-7.0)$, and similar to the $\mathrm{pH}$ of a viable epidermis (around pH 7.0) [28]. The ointment's $\mathrm{pH}$ is acceptable because the use of substances with neutral $\mathrm{pH}$ can maintain the physiological $\mathrm{pH}$ of the skin, preventing the overgrowth of microorganisms [29]. The T. crispa ointment exhibits thixotropy at $25^{\circ} \mathrm{C}$, which means that the viscosity decreases with increasing rate of shear. This rheological behavior is preferred due to its low flow resistance confirming the ointment's high spreadability, satisfying the ideal quality in topical application [30].

Assessment of irritation for a topical product, especially for a community-based ointment formulation, is a significant step in the determination of their acceptability and safety. The 0.00 PII score of the negative control ointment can be attributed to the previous non-irritancy claims of palm oil [31] and the inertness of candle wax [32]. On the other hand, the 0.15 PII score of T. crispa ointment, depicted as very slight erythema, may be due to various compounds extracted from the plant. The data gathered revealed that T. crispa extract has a negligible skin irritancy effect, inferring that the community-based ointment formulation of T. crispa is safe to be used topically.

The general activity of pediculicides occurs by penetrating the cuticle barrier on the skin of the lice and then disrupting the sodium channel in the nerve membrane, thereby causing delayed repolarization leading to impairment of the nerve responsible for breathing [33]. As a result, lice experience suffocation and expire. Permethrin, is one of the most extensively used pediculicide available in the market due to its great efficacy and wide margin of safety [34]. In the experiment, a small percentage of the lice treated with permethrin were still active after 180 min observation period. This may be attributed to lice that developed resistance against pyrethroids (i.e. permethrin). It is caused by a substitution of an amino acid in a protein responsible for "knockdown resistance", that results to insensitivity of the cholinergic nerves to pediculicides $[35,36]$. Although the source of the lice did not use permethrin or any pediculicides for the past month prior to collection, it may be caused by the transfer of permethrin-resistant head lice from another host. The prevalent occurrence of resistant head lice is due to misdiagnosis, overuse and improper use of pediculicides $[27,37]$. On the other hand, presence of inactive head lice in the group treated with palm oil was noted. Although it is anticipated for palm oil not to have any effect on the mortality of the lice, the presence of inactive head lice may be caused by the hydrophobic nature of the oil, which was reported to work by occluding the respiratory spiracle of the head louse [35]. Several papers have also reported that mayonnaise, petroleum jelly and olive oil are capable of causing mortality in head lice but only supplies transient period of stasis 
[22,36]. However, over $180 \mathrm{~min}$ period, it was observed that the percentage of head lice with no vital signs decreased and so it may also be due to a period of temporary stasis called "sham death" as insects (i.e., head louse) exhibit this ability when exposed to chemicals for less than $6 \mathrm{hr}[22,38]$. Head lice utilize their anatomical structure and physiologic characteristics to exhibit this ability as a defense mechanism when exposed to either too much water or to various chemicals that cause stupor, in a period insufficient to kill them $[39,40]$. This phenomenon is characterized by a momentary period where in head lice are thought to be inactive due to the absence of their gut and limb movements, but after some time they recommence and resume, respectively [39]. Fluctuations in the activities seen in all treatment groups may also be attributed to sham death.

It was confirmed that the community-based ointment formulation of T. crispa is an effective pediculicide, with the highest percent mortality $(78.60 \%)$ at 30 min post-treatment, and is comparable to the commercially available permethrin on the basis of pediculicidal efficacy on adult head lice. Although there was an observed decrease in the number of head lice considered to have no vital signs over time, T. crispa ointment still performed better than palm oil and relatively the same with permethrin. The efficacy of T. crispa may be attributed to the 3 compounds detected in the UPLC-qTOF/MS analysis. The 2 compounds were identified to be moupinamide and physalin I, and a third unknown compound with a m/z of 230.2471. The structural aspect of these compound may contribute to the pediculicidal efficacy [41-43]. Moupinamide belongs to the class benzenoids, and its direct parent methoxyphenol [44]. Studies have shown that benzenoids and methoxyphenol, have ability to elicit insecticidal activity, however their mode of action were not reported [41,45]. Physalin, on the other hand, belongs to the class of lipids [44] because of its steroidal nature. Lipids act on the spiracle of head louse and causes suffocation [35]. These studies provide supportive evidence for moupinamide and physalin I, as the compounds responsible for the pediculicidal efficacy of $T$. crispa ointment.

\section{ACKNOWLEDGMENTS}

We would like to express our sincerest gratitude to the Philippine Institute of Traditional and Alternative Health Care (PITAHC) for funding this project. We would also like to thank Ms. Camille Vien D. Sayson and Mr. Patrick Gabriel G. More- no for their technical assistance in the project.

\section{CONFLICT OF INTEREST}

The authors of this article have no issues that might lead to a conflict of interest.

\section{REFERENCES}

1. Diaz JH. The epidemiology, diagnosis, management, and prevention of ectoparasitic diseases in travelers. J Travel Med 2006; 13: 100-111.

2. McNair CM. Ectoparasites of medical and veterinary importance: drug resistance and the need for alternative control methods. J Pharm Pharmacol 2015; 67: 351-363.

3. Austin NI. Pediculosis among school children, in Owerri north local government area of Imo State, South Eastern Nigeria. Int J Infect Dis 2016; 45; 352-353.

4. Roberts RJ. Clinical practice. Head lice. N Engl J Med 2002; 346: 1645-1650.

5. Moshki M, Zamani-Alavijeh F, Mojadam M. Efficacy of peer education for adopting preventive behaviors against head lice infestation in female elementary school students: a randomised controlled trial. PLoS One 2017; 12: e0169361.

6. Sim S, Lee IY, Lee KJ, Seo JH, Im KI, Shin MH, Yong TS. A survey on head lice infestation in Korea (2001) and the therapeutic efficacy of oral trimethoprim/sulfamethoxazole adding to lindane shampoo. Korean J Parasitol 2003; 41: 57-61.

7. Greive K, Barnes T. In vitro comparison of four treatments which discourage infestation by head lice. Parasitol Res 2012; 110: 1695-1699.

8. Badiaga S, Brouqui P. Human louse-transmitted infectious diseases. Clin Microbiol Infect 2012; 18: 332-337.

9. Durand R, Bouvresse S, Berdjane Z, Izri A, Chosidow O, Clark JM. Insecticide resistance in head lice: clinical, parasitological and genetic aspects. Clin Microbiol Infect 2012; 18: 338-344.

10. Gupta A, Kaul N, Palma K. Isopropyl myristate $50 \%$ as a novel pediculicide in the treatment of head lice. J Am Acad Dermatol 2008; 58: AB8.

11. Verma P, Namdeo. Treatment of pediculosis capitis. Indian J Dermatol 2015; 60: 238-247.

12. Cabrera BD, Rampal L. A study on the problem of Pediculus humanus capitis infestation among primary school children in selected areas in the Philippines. Acta Med Philipp 1986; 22: $1-4$.

13. Heading Off Lice "Getting Rid of the Itchiness". cited 2017 Apr 5. Available from: http://m.thefilipinodoctor.com/health-care/ health-articles/499/.

14. Philippine Institute of Traditional and Alternative Health Care. cited 2016 Jun 9. Available from: https://pitahc.wordpress.com/ 2016/05/12/paggawa-ng-makabuhay-ointment-para-sa-galis- 
aso/.

15. Ragasa CY, Cruz MC, Gula R, Rideout JA. Clerodane diterpenes from Tinospora rumphii. J Nat Prod 2000; 63: 509-511.

16. Ahmad W, Jantan I, Bukhari SNA. Tinospora crispa (L.) Hook. f. \& Thomson: a review of its ethnobotanical, phytochemical, and pharmacological aspects. Front Pharmacol 2016; 7: 59.

17. Shukr MH, Metwally GF. Evaluation of topical gel bases formulated with various essential oils for antibacterial activity against methicillin-resistant Staphylococcus aureus. Trop J Pharm Res 2013; 12: 877-884.

18. Organization for Economic Cooperation and Development (OECD). Guideline for the testing of chemicals, 404: acute dermal irritation/corrosion. 2002.

19. Soiefer AI, Rauckman EJ. Toxicity associated with single chemical exposures. In Jabcoson-Kram D, Keller KA eds, Toxicology Testing Handbook Principles, Applications, and Data Applications. New York, USA. Marcel Dekker. 2001, pp 28.

20. Lehman AJ. Appraisal of chemicals in foods, drugs and cosmetics. The Association of Food and Drugs Officials of the United States. 1959, pp 46.

21. Wolf L, Eertmans F, Wolf D, Rossel B, Adriaens E. Efficacy and safety of a mineral oi-based head lice shampoo: a randomized, controlled, investigator-blinded, comparative study. PLoS One 2016; 11: e0156853.

22. Heukelbach J, Canyon DV, Oliveira FA, Muller R, Speare R. In vitro efficacy of over-the-counter botanical pediculicides against head louse Pediculus humanus var capitis based on a stringent standard for mortality assessment. Med Vet Entomol 2008; 22: 264-272.

23. Oladimeji FA, Orafidiya OO, Oqunniyi TAB, Adewunmi TA. Pediculicidal and scabicidal properties Lippia multiflora essential oil. J Ethnopharmacol 2000; 72: 305-311.

24. Dela Torre, GLT, Arollado, EC, Atienza AA, Manalo RAM. Evaluation of antioxidant capacity and identification of bioactive compounds of crude methanol extracts of Caesalpinia pulcherri$m a$ (L.) Swartz. Indian J Pharm Sci 2017; 79: 112-123.

25. Davarpanah MA, Kazerouni A, Rahmati H, Neirami RN, Bakhtiary H, Sadeghi M. The prevalence of pediculus capitis among the middle schoolchildren in Fars province, southern Iran. Caspian J Intern Med 2013; 4: 607-610.

26. Dalimi A, Mahdavi Poor B, Rashedi J, Asgharzadeh M, Abdolalizadeh J. Is hair lice still a public health problem? Iran J Public Health 2016; 45: 1671-1672.

27. Di Campli E, Di Bartolomeo S, Delli Pizzi P, Di Giulio M, Grande R, Nostro A, Cellini L. Activity of tea tree oil and nerolidol alone or in combination against Pediculus capitis (head lice) and its eggs. Parasitol Res 2012; 111: 1985-1992.

28. Lambers H, Piessens S, Bloem A, Pronk H, Finkel P. Natural skin surface $\mathrm{pH}$ is on average below 5 , which is beneficial for its resident flora. Int J Cosmet Sci 2006; 28: 359-3370.

29. Mukhopadhyay P. Cleansers and their role in various dermatological disorders. Indian J Dermatol 2011; 56: 2-6.

30. Dantas MG, Reis SA, Damasceno CM, Rolim LA, Rolim-Neto PJ,
Carvalho FO, Quintans-Junior LJ, Almeida JR. Development and evaluation of stability of a gel formulation containing the monoterpene borneol. ScientificWorldJournal 2016; 2016: 7394685.

31. Andersen FA. Final report on the safety assessment of Elaeis guineensis (palm) oil, Elaeis guineensis (palm) kernel oil, hydrogenated palm oil and hydrogenated palm kernel oil. Int J Toxicol 2000; 19: 7-28.

32. Caraccio TR, McGuigan MA. Over-the-counter products. In Dart RC ed, Medical Toxicology. Philadelphia, USA. Lippincott Williams \& Wilkins. 2004, pp 1059.

33. Connolly M. Recommended management of head lice and scabies. Prescriber 2013; 24: 17-29.

34. Mac-Mary S, Messikh R, Jeudy A, Lihoreau T, Sainthillier JM, Gabard B, Schneider C, Auderset P, Humbert P. Assessment of the efficacy and safety of a new treatment for head lice. ISRN Dermatol 2012; 2012: 460467.

35. Paller AS, Mancini AJ. Hurwitz Clinical Pediatric Dermatology. 5th ed. Canada. Elsevier Health Sciences. 2016, pp 439.

36. Burkhart CN, Burkhart CG. Recommendation to standardize pediculicidal and ovicidal testing for head lice (Anoplura; pediculidae). J Med Entomol 2001; 38: 127-129.

37. Burkhart CG. Relationship of treatment-resistant head lice to the safety and efficacy of pediculicides. Mayo Clin Proc 2004; 79: 661-666.

38. Oliveira FA, Speare R, Heukelbach J. High in vitro efficacy of Nyda L, a pediculicide containing dimeticone. J Eur Acad Dermatol Venereol 2007; 21: 1325-1329.

39. Nuttall GHF. The biology of Pediculus humanus. Parasitology 1917; 10: 80-185.

40. Burkhart CN, Burkhart CG, Gunning WT. Scanning electron microscopy of adult head lice (Pediculus humanus capitis) with focus on clinical implications. J Cutan Med Surg 2000; 4: 181-185.

41. Bagavan A, Rahuman AA, Kamaraj C, Elango G, Zahir AA, Jayaseelan C, Santhoshkumar T, Marimuthu S. Contact and fumigant toxicity of hexane flower bud extract of Syzygium aromaticum and its compounds against Pediculus humanus capitis (phtiraptera: pediculidae). Parasitol Res 2011; 109: 1329-1340.

42. Priestley CM, Burgess IF, Williamson EM. Lethality of essential oil constituents towards the human louse, Pediculus humanus, and its eggs. Fitoterapia 2006; 77: 303-309.

43. Rossini C, Castillo L, González A. Plant extracts and their components as potential control agents against human head lice. Phytochem Rev 2008; 7: 51-63.

44. Afendi FM, Okada T, Yamazaki M, Hirai-Morita A, Nakamura K, Ikeda S, Takahashi H, Ataf-Ul-Amin M, Darusman LK, Saito K, Kanaya S. KNApSAcK family databases: integrated metaboliteplant species databases for multifaceted plant research. Plant Cell Physiol 2012; 53: 1-12.

45. Silva CGV, Zago HB, Hugo JGS, da Camara CAG. Composition and insecticidal activity of the essential oil of Croton grewioides Baill. against Mexican bean weevil (Zabrotes subfasciatus Boheman). J Essent Oil Res 2012; 20: 179-182. 